\title{
DIFFERENTIATION OF THE NUCLEI OF POLLEN GRAINS
}

\author{
P. G. MARTIN \\ Department of Zoology, University of Adelaide
}

Received 25.iv.59

\section{INTRODUCTION}

THe hypothesis which is most frequently used to explain how two daughter cells become different is that, although chromosomal components are distributed equally at mitosis, cytoplasmic components may not be; differentiation must result, ultimately, from an initial cytoplasmic difference. This is shown, for example, by the differentiation of the nuclei in the pollen grains of angiosperms. La Cour (1949) found that therewas an unequal distribution of ribonucleoprotein (RNP). After mitosis, one daughter nucleus, that which arrived in the area rich in RNP, became the large, diffuse vegetative nucleus. The other arrived in an area with little RNP and became the small, dense generative nucleus. La Cour concluded that nuclear differentiation was a response to cytoplasmic differentiation.

On the other hand, King and Briggs (r955), who studied developing frog embryos, found that nuclei showed stable changes in their capacity to promote differentiation. In this case, nuclear differentiation was a cause of further differentiation.

The general hypothesis with which the present study commenced was that if a difference between daughter nuclei could be demonstrated at telophase of mitosis, i.e. before differentiation had commenced, then the difference might reasonably be thought to be a cause of subsequent differentiation. Such a difference would not usually be expected in chromosome number nor in DNA content. The nuclear component chosen for study was basic protein because this had been shown to vary from tissue to tissue (Cruft et al., r954). Moreover, quantitative microphotometric estimation was practicable, Alfert and Geschwind (1953) having proposed a method of staining which was thought to be specific for histones or, more accurately, basic proteins with high isoelectric points.

If an unequal distribution of basic protein causes differentiation, it would not be expected at mitoses giving rise to a uniform tissue. The first mitosis in the pollen grain of an angiosperm was chosen for study because the daughter nuclei from this division have quite different fates.

\section{MATERIALS AND METHODS}

Species studied were Zea mays L. and Agave attenuata Salm-Dyck. Both species were diploid with regular meiosis and high pollen fertility. Buds were fixed in 
Io per cent. neutral formalin. In agave, the perianth parts were removed and the tips of anthers were cut. A single anther from a bud was examined and, if pollen was found to be undergoing the first mitosis, the rest of the bud was retained for further study. Selected buds were washed overnight in running water, dehydrated in tertiary butyl alcohol and embedded in paraffin wax (Johanssen, I940, p. I 30). Sections were cut $30 \mu$ thick, mounted and stained by the method of Alfert and Geschwind (1953) in 0.1 per cent. fast green FGF (George T. Gurr, London) at $p \mathrm{H} 8.0$ after extracting nucleic acids in 5 per cent. trichloroacetic acid (TCA) at $90^{\circ} \mathrm{C}$. for 15 minutes. Following differentiation of the staining in 95 per cent. alcohol, slides were dehydrated and mounted in neutral mounting medium.

In their description of the staining method, Alfert and Geschwind (r953) used onion root tips as a representative plant tissue. As a check on the staining methods, root tips of onion and maize were fixed and embedded at the same time as anthers; slides carrying sections I $2 \mu$ thick were treated simultaneously with the sections of anthers.

Unexpectedly, nucleoli in the pollen grains stained deeply. Between late prophase and telophase, the chromosomes also stained deeply. However, most pollen grains, including all those on which measurements were made, were either mononucleate and at late interphase or early prophase, or binucleate and at early interphase. In these, the nuclei were not suitable for microphotometric measurement because they were lightly stained and ill-defined in comparison with the nucleolus, to which all measurements were confined.

Slides of agave and maize were chosen for measurement if the sections of anthers contained mostly pre-mitotic pollen grains and relatively few post-mitotic. The positions of all post-mitotic pollen grains were noted and were then inspected in turn to see whether they could be measured. They were rejected only if $(a)$ one or both nucleoli were at the upper or lower limit of the section and apparently cut, or $(b)$ the two nucleoli were over-lapping or one or both screened by a fold in the pollen grain wall, debris or another pollen grain. Once selected, no pollen grain was subsequently rejected. Pre-mitotic pollen grains were numerous and the nearest to a measured post-mitotic grain was chosen for measurement unless rejected for one of the reasons already listed. It was thought that, in this way, a random sample was obtained. Thirty pre-mitotic and thirty pairs of post-mitotic nucleoli were measured on each slide. Two slides of maize and two of agave, each prepared at a different time, were used.

A screw micrometer eyepiece was used to measure the nucleolar diameters and the average of two measurements at right-angles was taken as the nucleolar diameter for calculating volume. Extinctions were measured with the Lison histophotometer (Electrophysique S.A., Brussels). A Philips Er4 50-watt microscope lamp was used as a source of light. Using a $50 \times$ fluorite oil-immersion objective (N.A. I.o) an image was projected on a screen in the centre of which was a hole of $2 \mathrm{~mm}$. diameter. This was equivalent to 70 per cent. of the diameter of the smallest nucleolus measured and 27 per cent. of the largest. Behind the hole was a Wratten ${ }_{72} \mathrm{~B}$ filter and behind this a photoelectric cell. A blank reading was taken immediately adjacent to the nucleolus to be measured and the galvanometer adjusted to Ioo. The slide was then moved so that the nucleolus was centred over the hole and the transmittance read. The amount of fast green stain, in arbitrary units, was calculated from the formula $\frac{\mathrm{EC}^{2}}{\mathrm{~F}} \cdot$ where $\mathrm{E}$ is the extinction $\left(\log \frac{\mathrm{I}}{\text { Transmittancc }}\right)$ and $\mathrm{F}$ the fraction of the volume of the nucleus included in the central plug, of radius $c$, whosc cxtinction was measured. $\mathrm{F}=\frac{\mathrm{I}-\left(r^{2}-c^{2}\right)^{\frac{3}{2}}}{r^{3}}$ where $r$ is the radius of the nucleus, assumed to be spherical (Swift, r950).

An estimate of the accuracy of the method was obtaincd as follows. A solution of polyvinyl alcohol in water, and of approximately the same refractive index as 
paraffin oil, was used to dissolve fast green FCF. A drop of this solution was then mixed with paraffin oil on a slide, covered with a cover slip, and the resulting spherical bubbles were examined. To prevent flattening and movement under the oilimmersion objective, the slide had several $20 \mu$ de-waxed sections adhering to it. Fifty bubbles were measured under conditions similar to those used in the maize and agave experiments and over the same range of diameters. The fraction $\frac{\text { amount }}{\text { volume' }}$ i.e. the concentration, which should have been constant, was plotted against the

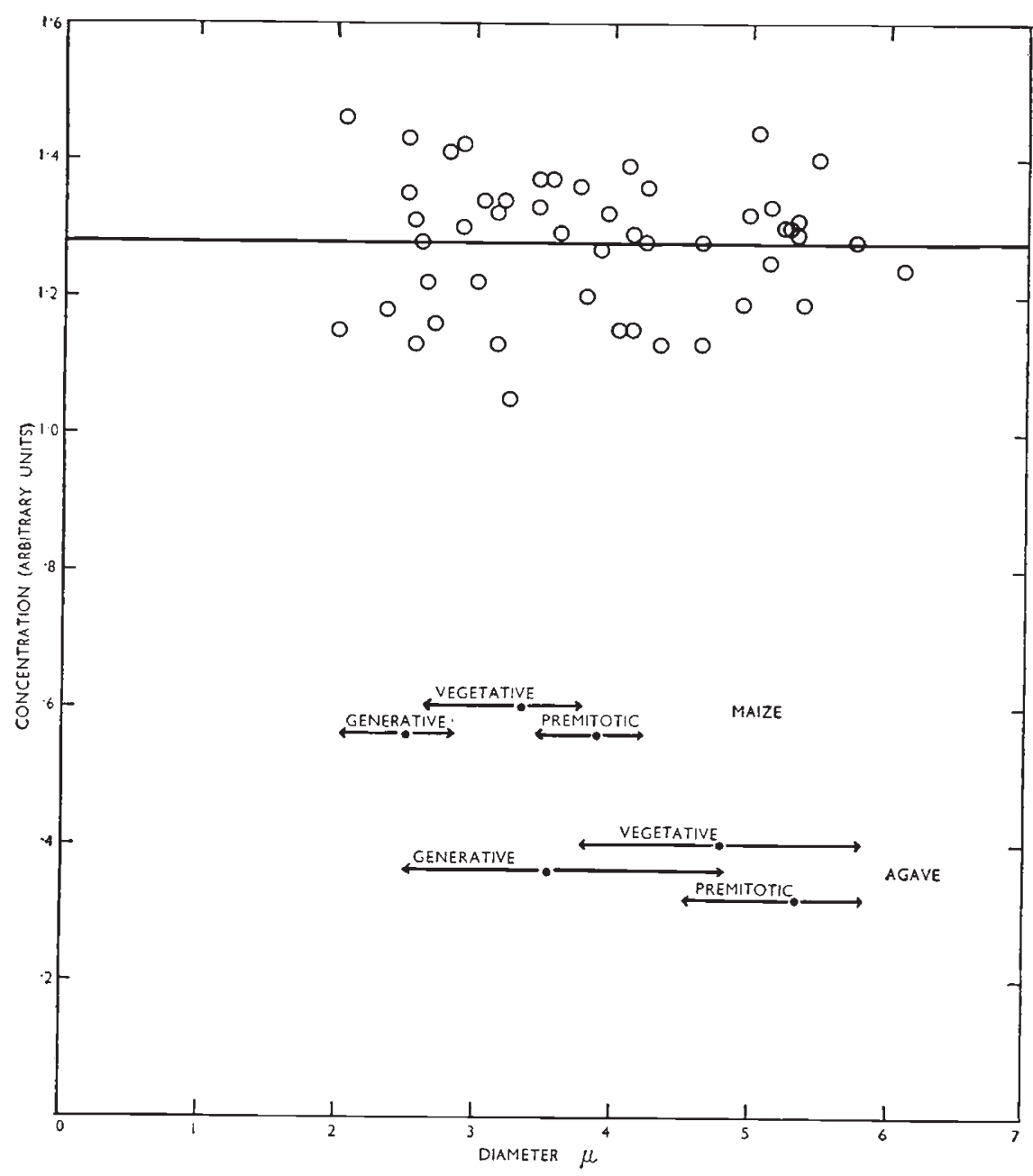

TexT-FIG. 1.-Above: Measurements of the concentration of stain in spherical aqueous droplets in paraffin oil show that the standard error inherent in the method is 8 per cent. Errors are distributed at random with respect to diameter of droplet. Below : The means and ranges of the diameters of the six classes of nucleoli studied.

diameter. The results are given in the upper part of fig. I. The standard deviation was 8 per cent. of the mean but the errors were distributed at random to the size of the droplets. This variance, though larger than might have been desired, would add a random but not a systematic error to the measurements of the experiments. 


\section{RESULTS}

In the onion root tips the staining was similar to that described by Alfert and Geschwind (1953); i.e. it was confined to the nuclei but not the nucleoli and, in mitotic cells, to the chromosomes (plate, fig. I). In the pollen grains, the stain was also confined to nuclei and chromosomes but, as already mentioned, the nucleoli stained deeply and consistently (plate, figs. 2-7). That this was a tissue and

TABLE I

Amounts of fast green (in arbitrary units) in nucleoli of pollen grains

\begin{tabular}{|c|c|c|c|c|}
\hline Nucleus & $\begin{array}{l}\text { Maize, } \\
\text { slide I }\end{array}$ & $\begin{array}{l}\text { Maize, } \\
\text { slide } 2\end{array}$ & $\begin{array}{l}\text { Agave, } \\
\text { slide I }\end{array}$ & $\begin{array}{l}\text { Agave, } \\
\text { slide } 2\end{array}$ \\
\hline $\begin{array}{l}\text { Vegetative . } \\
\text { Generative . } \\
\text { Sum of vegetative }+ \text { generative } \\
\text { Pre-mitotic. }\end{array}$ & $\begin{array}{l}1 \cdot 48 \pm 0.33 \\
0.78 \pm 0 \cdot 18 \\
2 \cdot 26 \pm 0 \cdot 45 \\
2 \cdot 37 \pm 0.36\end{array}$ & $\begin{array}{l}1 \cdot 36 \pm 0 \cdot 26 \\
0 \cdot 71 \pm 0 \cdot 19 \\
2 \cdot 07 \pm 0 \cdot 40 \\
2 \cdot 12 \pm 0 \cdot 24\end{array}$ & $\begin{array}{l}3 \cdot 99 \pm \mathrm{r} \cdot 03 \\
\mathrm{I} \cdot 6 \mathrm{I} \pm \mathrm{0} \cdot 58 \\
5 \cdot 60 \pm \mathrm{I} \cdot 48 \\
5 \cdot 40 \pm \mathrm{r} \cdot 28\end{array}$ & $\begin{array}{l}3 \cdot 62 \pm 0 \cdot 61 \\
1 \cdot 47 \pm 0 \cdot 28 \\
5 \cdot 09 \pm 0 \cdot 81 \\
5 \cdot 18 \pm 0.79\end{array}$ \\
\hline
\end{tabular}

not a species difference was shown by staining maize root tips in which the nucleoli, as in onion, remained unstained.

The nucleolus was regularly circular in outline, e.g. in the vegetative nuclei of agave, the mean of the differences between the two measured

TABLE 2

Concentrations, in arbitrary units, in nucleoli

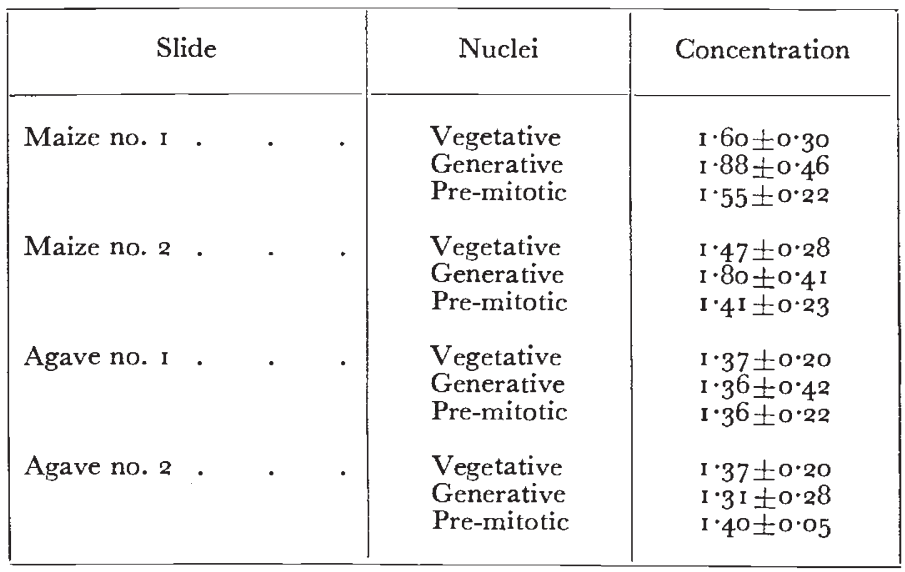

diameters was 5.7 per cent. of the mean diameter. More than one nucleolus per nucleus was never observed. There was never any difficulty in telling the generative from the vegetative nucleus. They could be distinguished even at the earliest stage when they were still nearly touching.

Results are shown in table I. The amount of stain in the vegetative nucleoli significantly exceeds that in the generative ones in all cases. 
In maize, the amount in the vegetative nucleolus was approximately double that in the generative nucleolus and, in agave, more than double. In all four experiments the mean of the sums of the amounts of stain in the pairs of vegetative and generative nucleoli did not differ from the mean of the amount in the pre-mitotic nucleoli.

In table 2 the concentrations of stain (calculated from the amount of stain and volume) in the different classes of nucleoli are shown. In agave the concentrations in all three classes were the same and, in maize, the vegetative and pre-mitotic nucleoli did not differ. But the concentration in the generative nucleoli in maize was approximately 24 per cent. higher than in the pre-mitotic nucleoli and 20 per cent. higher than in the vegetative nucleoli, these differences being highly significant.

\section{DISCUSSION}

The observation that, under apparently similar conditions, the nucleoli in onion and maize root tips do not stain, whereas in the pollen grains of maize and agave they do, suggests that nucleoli may vary in their content of basic protein. There has been some confusion on this subject, Caspersson (1950) and Serra and Queirez Lopez (1944) having reported that nucleoli contain basic protein while Pollister and Ris (I947) and Vincent (I952) were unable to confirm this. The observations presented here give some direct evidence in support of the conclusion of Vincent (I955) that nucleoli might contain varying amounts of basic proteins depending on the metabolic activities of the cells.

On their own, the data in table I may be taken to mean that the stain was specific to basic protein, that the basic protein of the premitotic nucleolus was divided unequally and without loss to the daughter nuclei where it was reconstituted into nucleoli which were measured before any new synthesis occurred after mitosis. The data in table 2 make it necessary to re-examine these conclusions. The observations that the concentration of stain was the same in all three classes of nuclei in agave and was also the same in two classes of nuclei in maize, permit of two alternative explanations. Either the stain was specific for basic protein and the amount of this determined the volume of the measured body; or the stain was not specific for basic protein but was taken up in the same concentrations by each nucleolus, the amount of stain merely reflecting its volume. It is not possible to choose rigorously between these two alternatives but the former seems more likely for two reasons. Firstly, the experiments of Alfert and Geschwind (I 953), Ansley (I954), Bloch and Godman (I955a, I955b), Alfert (1956) and Horn and Ward (1957) suggest that the stain is specific for basic proteins and the evidence already presented on localisation of the stain does not give any reason to doubt this specificity. Secondly, the aberrant class of nucleoli in table 2 (the generative nucleoli of maize) was the smallest of all six classes. If the stain had 
been taken up in equal concentration in all nucleoli, this would imply that the concentration had been overestimated in the smallest nucleoli. This seems unlikely from the results shown in fig. I. Moreover, as the diameter became smaller and approached the diameter of the plug, one would expect that consequent errors, arising from eccentricity, would have resulted in an underestimation of concentration. It seems more likely that, in the generative nucleolus of maize, the amount of stain correctly indicated the amount of basic protein but the relationship between amount of basic protein and the measured volume broke down for some unknown reason. The most reasonable interpretation of the data is that, at mitosis, the basic protein of the pre-mitotic nucleolus was divided unequally and without loss between the vegetative and generative nucleoli.

The idea of a self-duplicating capacity of thc nucleolus is not new. Brachet (I957, p. I53) states, "This cell organelle is supposed to disappear at prophase and to be re-synthesised at telophase. But it is by no means impossible that essential constituents of the nucleoli are equally distributed into the two daughter cells by the chromosomes". The observations that the sums of the amounts of fast green in the two post-mitotic nucleoli equalled that in the pre-mitotic nucleoli suggests that basic proteins are so distributed. In these experiments, however, the distribution was unequal.

The mechanism by which this might be effected is obscure. RNA (Swift et al., r 956), zinc (Fujii, I954) and alkaline phosphatase (Chevremont and Firket, I953) appear on the chromosomes as soon as the nucleoli disappear. Vincent (1955) concluded that, at telophase, nucleolar materials are found along the surface of the entire chromosome complement and that these materials aggregate and fuse at the site of the nucleolar organiser. Observations in the present work are not incompatible with this scheme (plate, figs. 4-7). If it is correct, it suggests that, when the nucleolus disintegrates at prometaphase, basic proteins are distributed over the chromosome complement and, at the following telophase, stripped off to form new nucleoli. A consistently unequal distribution at anaphase could be caused by an uneven distribution of basic proteins at prometaphase and a response of all the more heavily charged daughter chromosomes to a gradient along the spindle. That such a gradient exists at the first pollen grain mitosis was shown by La Cour (I 949) and Müntzing (I946).

Although the mechanism must remain speculative, the evidence does suggest that there is an unequal distribution of nuclear material at mitosis. This, like the uneven distribution of cytoplasmic material which precedes it (La Cour, 1949), may be important in the differentiation of the nuclei of pollen grains.

\section{SUMMARY}

I. Using a fast green staining procedure thought to be specific for basic proteins, it was found that nucleoli in pollen grains of Zea mays 
In each figure the stain used was fast green $\mathrm{FCF}$ at $p \mathrm{H} 8 \cdot 0$ following fixation in neutral to per cent. formalin and removal of nucleic acids. All magnifications $\times 940$.

FIG. I.-Allium cepa. Root tip showing nuclei and chromosomes stained, nucleoli not stained.

FIG. 2.-Agave attenuata. Pollen grains showing nucleoli typical of those on which measurements were made. Top, pre-mitotic; bottom, post-mitotic.

Fig. 3.-Zea mays. Pollen grains showing nucleoli typical of those on which measurements were made. Top and centre, pre-mitotic; bottom, post-mitotic.

Figs. 4-7.-Zea mays. The first mitosis in the pollen grain; 4-late prophase showing nucleolus and chromosomes ; 5-metaphase; 6-telophase ; 7-late telophase, nucleoli reforming. 
and Agave attenuata stained, while nucleoli in the root-tips of Zea mays and Allium cepa did not stain.

2. Unequal amounts of fast green stain were present in the generative and vegetative nucleoli after the first mitosis in the pollen grains of Zea mays and Agave attenuata.

3. The sum of the amounts in the post-mitotic nucleoli did not differ from the amount in the pre-mitotic nucleoli.

4. The data are interpreted as meaning that, at mitosis, basic protein of the pre-mitotic nucleolus was divided unequally and without loss between the vegetative and generative nucleoli.

5. The possibility that this may be a cause of differentiation is discussed.

Acknowledgments.-I should like to thank Professor W. P. Rogers and Dr H. G. Andrewartha for their advice and criticism and Miss G. A. Gooden for her valuable assistance.

\section{REFERENCES}

ALFERT, M. 1956. Chemical differentiation of nuclear proteins during spermatogenesis in the salmon. 7. Biophys. Biochem. Cytol., 2, I09-1 I4.

ALFERT, M., AND GESCHWind, I. I953. A selective staining method for the basic proteins of cell nuclei. Proc. Natl. Acad. Sci. U.S., 39, 99 I-999.

ANSLEY, H. R. 1954. A cytological and cytophotometric study of alternative pathways of meiosis in the house centipede (Scutigera forceps Rafinesque). Chromosoma, 6, 656-695.

BLOGH, D. P., AND GODMAN, G. C. I955a. A microphotometric study of the synthesis of DNA and nuclear histone. $\mathcal{F}$. Biophys. Biochem. Cytol., 1,1 i 7-28.

BLOGH, D. P., AND GODMAN, G. C. 1955b. Evidence of differences in the deoxyribonucleo-protein complex of rapidly proliferating and non-dividing cells. $\mathcal{F}$. Biophys. Biochem. Cytol., r, 531-550.

BRACHeT, J. 1957. Biochemical Cytology. New York, Academic Press Inc.

CAspersson, t. o. 1950. Cell Growth and Cell Function. Norton, New York.

CHEVREMONT, M., AND FIRKET, H. 1953. Alkaline phosphatase of the nucleus. Intern. Rev. Cytol., 2, 26I-288.

CRUfT, h. J., MAURITZen, C. M., AND STEDman, E. I954. Abnormal properties of histones from malignant cells. Nature, $174,580$.

FujII, T. 1954. Presence of zinc in nucleoli and its possible role in mitosis. Nature, I74, I 108.

HORN, E. C., AND WARD, C. L. 1957. The localisation of basic proteins in the nuclei of larval Drosophila salivary glands. Proc. Natl. Acad. Sci. U.S., 43, 776-779.

Johanssen, D. A. I940. Plant Microtechnique. McGraw-Hill Book Co. Inc., New York and London.

KING, T. J., AND BRIGGS, R. 1955. Changes in the nuclei of differentiating gastrula cells, as demonstrated by nuclear transplantation. Proc. Natl. Acad. Sci. U.S., 4 I, $321-325$.

LA COUR, L. F. I949. Differentiation in the pollen grain. Heredity, 3, 319-337.

мüNTZING, A. 1946. Cytological studies of extra fragment chromosomes in rye. III. The mechanism of non-disjunction at the pollen mitosis. Hereditas, 32, I27-1 29 .

POLLISTER, A. W., AND RIS, H. 1947. Nucleoprotein determination in cytological preparations. Cold Spring Harbor Symp. Quant. Biol., 12, I47-I 57.

SERrA, J. A., AND QUeIReZ lOPeZ, A. 1944. Direkter Nachweis basischer Proteine in den Chromosomen und im Nukleolus. Naturwissenschaften, 32, 47. 
stedman, E., And stedman, E. 1947. The chemical nature and functions of the components of cell nuclei. Cold Spring Harbor Symp. Quant. Biol., 12, 224-236.

swrft, н. н. 1950. The deoxyribose nucleic acid content of animal nuclei. Physiologic. Zool., 23, г69-198.

SWIFT, H. H., REBHUN, L., RASGH, E., AND WOODARD, J. 1956. The cytology of nuclear RNA. In Cellular Mechanisms of Differentiation and Groweth (D. Rudnick, ed.), pp. 45-59, Princeton Univ. Press, Princeton, New Jersey.

vincent, w. s. 1952. The isolation and chemical properties of the nucleoli of starfish oocytes. Proc. Natl. Acad. Sci. U.S., 38, 139-145.

vincent, w. s. 1955. Structure and chemistry of nucleoli. Intern. Rev. Cytol., 4, 269-298. 